\section{Two small-volume electrochemical cells for the measurement of surface enhanced Raman scattering}

\section{Otto, A van Welie, E de Jong, F F M de Mul, J Mud and \\ J Greve \\ Twente University of Technology, Department of Applied}

Physics, PO Box 217, 7500 AE Enschede, The Netherlands

Received 15 September 1983, in final form 20 December 1983

Abstract. Two electrochemical cells, for performing surface enhanced Raman scattering (SERS), with submillilitre volumes are presented. One of the cells is especially developed for use in a Raman microspectrometer. The smallest cell uses only $80 \mu \mathrm{l}$ of sample. SER measurements are performed on $2 \times 10^{-3} \mathrm{M}$ adenine.

\section{Introduction}

Many molecules show an enormous increase in Raman scattering cross section if they are adsorbed on the surface of an electrochemically roughened silver electrode. This increase can be as large as a factor of $10^{7}$. With surface enhanced Raman scattering (Chang and Furtak 1982) (SERS), as the effect has been called, the measured spectral intensity is largely due to molecules adsorbed by the electrode surface. This means that, in principle, only very small amounts of material are needed. This is especially advantageous in the study of biological compounds which are not available in large amounts since they are hard to prepare or may be very expensive.

In most studies of SERS no special attention was paid, however, to the miniaturisation of the electrochemical cells used. The volumes of SERS cells mentioned in the literature range from $50 \mathrm{ml}$ (Chen et al 1982) down to $15 \mathrm{ml}$ (Ervin et al 1980). To take full advantage of the possibility to use very small amounts of material we have designed and tested two electrochemical SERS cells in the submillilitre range. We use the terms mini- and

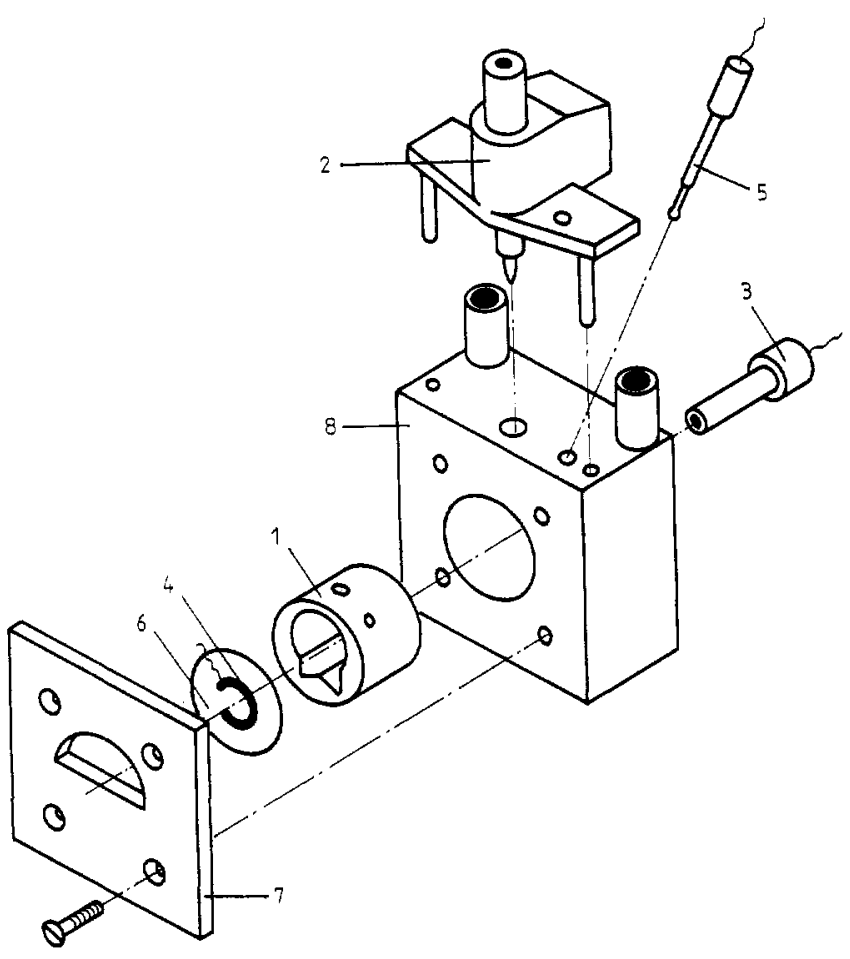

Figure 1. An exploded view of the minicell. (1), Teflon inner cell; (2), support for the reference electrode + capillary;

(3), working electrode; (4), counter electrode; (5), thermocouple; (6), glass window; (7), brass coverplate; (8), brass frame with channels.

micro SERS cell for these two cells which have volumes of 800 and $80 \mu \mathrm{l}$ respectively. The minicell is intended for use in a normal Raman spectrometer. In our setup the angle between the incoming beam and the electrode surface can be chosen. An angle of $45^{\circ}$ is used in the experiment. A lens with a focal length of $400 \mathrm{~mm}$ is used to produce a spot which covers a surface area of $3.4 \times 10^{-8} \mathrm{~m}^{2}$. The scattered light is collected in the direction normal to the electrode surface.

The microcell is for use in a Raman microspectrometer using epi-illumination. By choice of the objective used in the microscope and regulation of the beam diameter one can

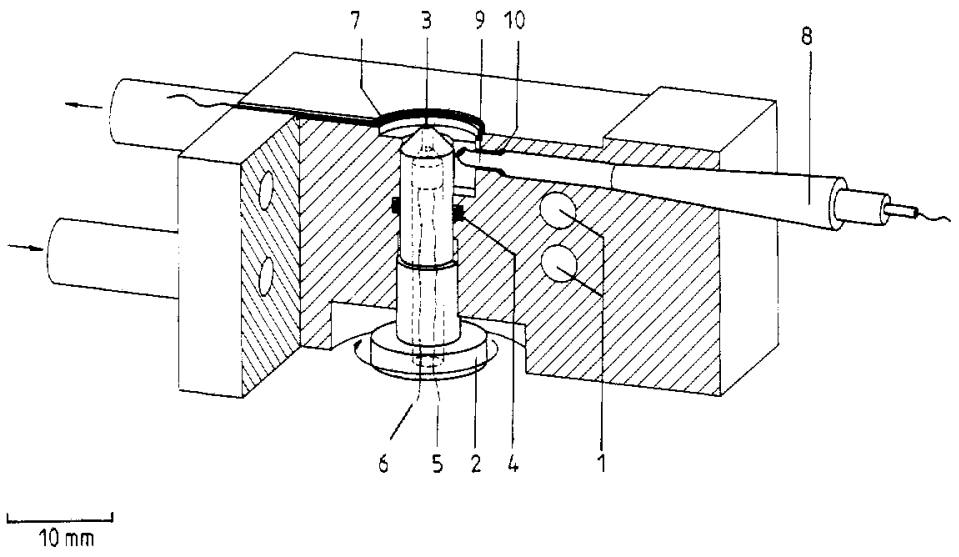

Figure 2. The microcell. (1), water channels; (2), perspex rod; (3), the working electrode; (4), rubber ring; (5), insulated wire connecting the working electrode; (6), thermocouple; (7), counter electrode; (8), reference electrode; (9), capillary; (10), rubber ring. 
produce spot diameters down to $0.8 \mu \mathrm{m}$ diameter (Buiteveld $e t$ al 1982). Both cells are equipped with a three-electrode system. The working electrode is made of silver and cylindrically shaped. The counter electrode is a platinum wire of circular shape. The reference electrode in the minicell is a saturated calomel electrode (SCE). An $\mathrm{Ag} / \mathrm{AgCl}$ electrode of small dimensions was constructed for use in the microcell. The temperature of both cells can be regulated by pumping water through appropriate channels in the walls of the cells. Both cells can easily be cleaned and sterilised and are chemically inert.

\section{The minicell}

An exploded view of the minicell is presented in figure 1. It consists of a brass frame and a Teflon inner part which fits tightly in the brass frame. Because Teflon is a poor heat conductor we have minimised the thickness of the walls. The diameter of the silver working electrode is $3 \mathrm{~mm}$. The electrode is fitted in a Teflon rod which can be inserted in the cell from the back of the cell. The front-side of the cell is closed by a glass window pressed against the Teflon inner part with a brass cover plate. The capillary providing the electric connection between the working electrode and the reference electrode, and the glass casing containing the thermocouple can be inserted from above. The cell is equipped with an induction-driven magnetic stirrer. The volume of the cell is about $800 \mu l$.

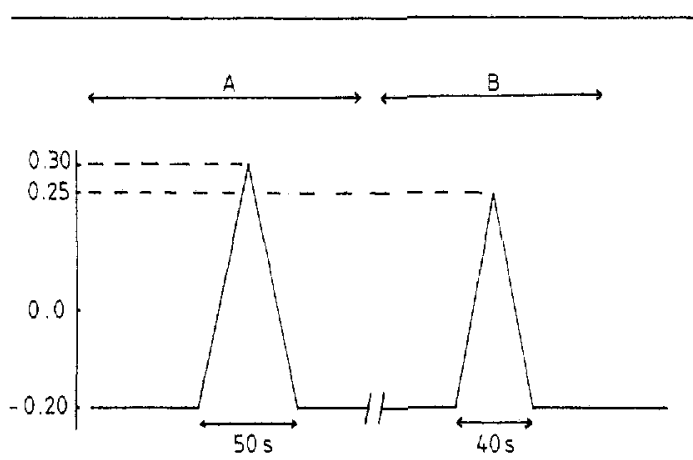

Figure 3. Voltage against time during the electrochemical roughening procedure used. Part $A$ takes place in $10^{-1} \mathrm{M} \mathrm{KCl}$ and $10^{-3} \mathrm{M} \mathrm{Na}_{2} \mathrm{HPO}_{4}$. Part $\mathrm{B}$ takes place in $10^{-1} \mathrm{M} \mathrm{KCl}$, $10^{-3} \mathrm{M} \mathrm{Na}_{2} \mathrm{HPO}_{4}$ and $2 \times 10^{-3} \mathrm{M}$ adenine.
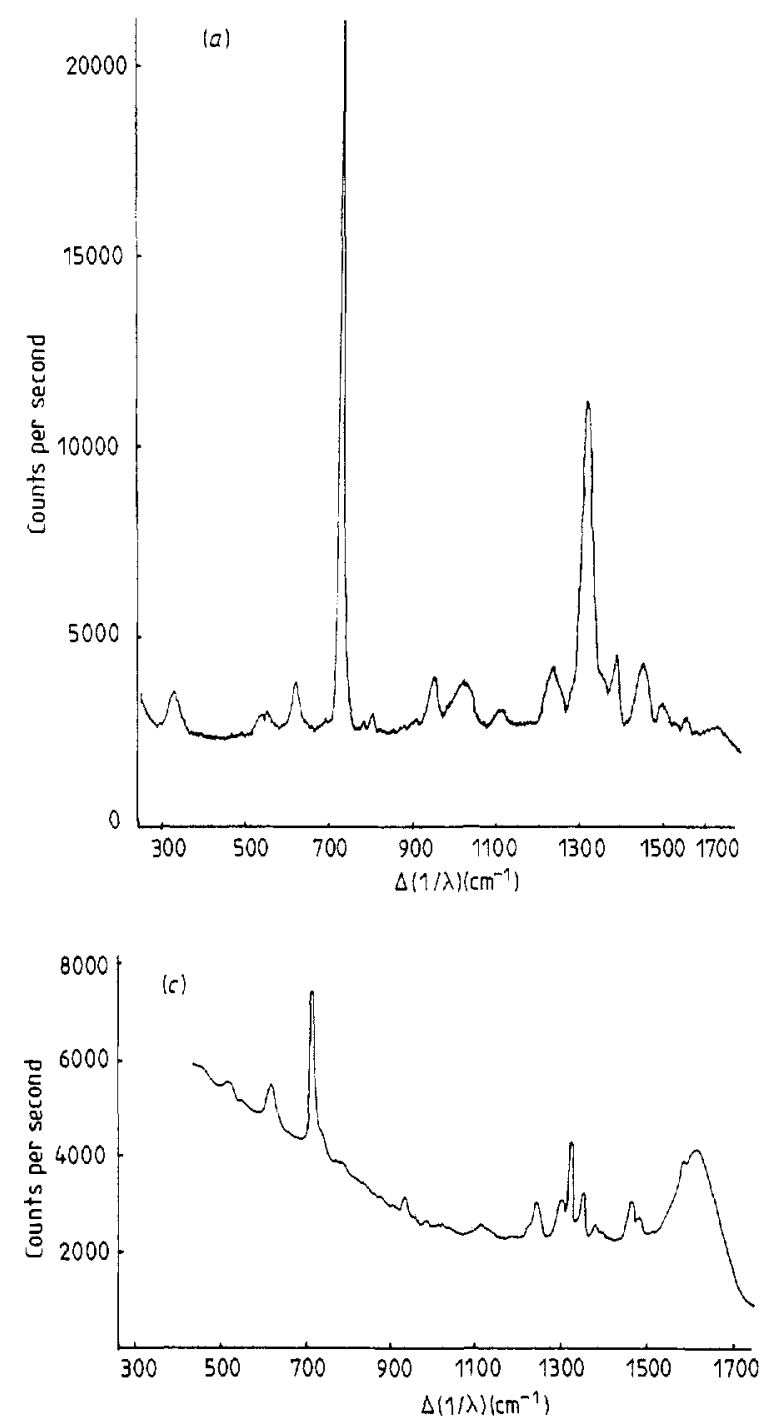

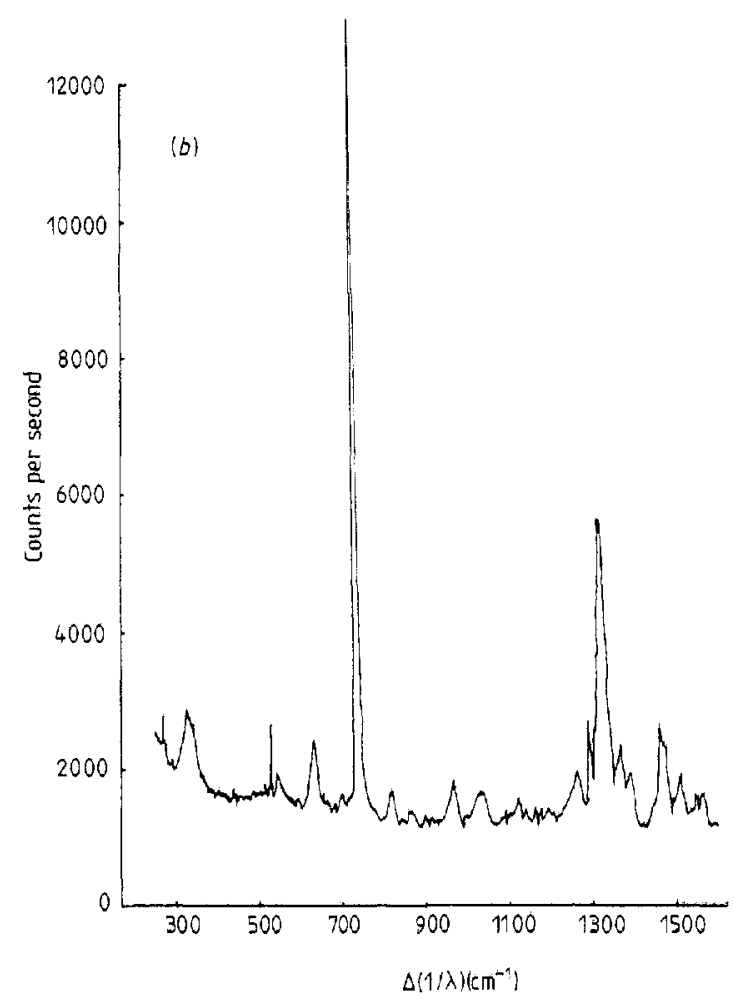

Figure 4. (a), Minicell: SERS spectrum of $6 \times 10^{-3} \mathrm{M}$ adenine in $10^{-1} \mathrm{M} \mathrm{KCl}$ and $10^{-3} \mathrm{M} \mathrm{Na}_{2} \mathrm{HPO}_{4}, \mathrm{pH}=0.75$. Laser power at the electrode, $75 \mathrm{~mW}$; irradiance, $2.2 \times 10^{6} \mathrm{~W} \mathrm{~m}^{-2}$; $\lambda=514.5 \mathrm{~nm}$; spectral resolution, $4 \mathrm{~cm}^{-1}$; scan speed, $50 \mathrm{~cm}^{-1}$ $\min ^{-1}$; int. time, $1 \mathrm{~s}$; electrode potential, $-0.6 \mathrm{~V}$ against SCE. (b), microcell: SERS spectrum of $2 \times 10^{-43} \mathrm{M}$ adenine in $10^{-1} \mathrm{M}$ $\mathrm{KCl}$ and $10^{-3} \mathrm{M} \mathrm{Na}_{2} \mathrm{HPO}_{4}, \mathrm{pH}=7.5$. Laser power at the electrode, $1 \mathrm{~mW}$; irradiance, $2.6 \times 10^{7} \mathrm{~W} \mathrm{~m}^{-2} ; \lambda=514.5 \mathrm{~nm}$; spectral resolution, $3.2 \mathrm{~cm}^{-1}$; scan speed, $50 \mathrm{~cm}^{-1} \mathrm{~min}^{-1}$; int. time, $1 \mathrm{~s}$; objective, $40 \times$; numerical aperture, 0.65 ; spot diameter, $7 \mu \mathrm{m}$. (c), normal Raman scattering spectrum of $6.6 \times 10^{-2} \mathrm{M}$ in water, $\mathrm{pH}=9.8$. 


\section{The microcell}

Using a Raman microspectrometer we are able to focus the laser beam to $0.8 \mu \mathrm{m}$ diameter. To be able to use epi-illumination with high numerical aperture light collection a small distance between objective and SERS electrode has to be realised. Using substage illumination the SERS cell has to be transparent. In the following design these demands could be matched.

The working electrode, with a diameter of $0.5 \mathrm{~mm}$, is fitted in a perspex rod. The perspex rod can be screwed into a perspex frame. This provides the possibility to position the electrode surface at the proper working distance of the particular objective used. With the use of this construction the surface of the electrode could clearly be seen through the microscope. A detailed drawing of the microcell is shown in figure 2. The temperature of the cell is measured by a thermocouple pressed against the back of the working electrode. With this construction we can measure the temperature of the adsorbed molecules to within $1 \mathrm{~K}$. The temperature is not measured during anodisation procedures to prevent short circuiting. The volume of the cell is $80 \mu$ l.

\section{Results}

The Raman spectrometer consists of a Coherent argon-ion laser and Jobin-Yvon HG 2S monochromator. An EMI 9862B photomultiplier tube is used for photon counting. A Nikon Optiphot microscope is attached to the monochromator in a microprobe arrangement in which the microcell is used.

A potentiostat is used for regulation and stabilisation of electrode potentials. In order to check the reliability of the SERS cells, we performed experiments on adenine. Before the working electrode is placed in the cell it is mechanically polished with SIANOR B 5/0 emery paper and cleaned with deionised water. Secondly preceding the actual measurement, the silver electrode is electrochemically roughened using a cycle shown in figure 3. Part $\mathrm{A}$ of the cycle takes place in a solution containing $100 \mathrm{mM}$ $\mathrm{KCl}$ and $1 \mathrm{mM} \mathrm{Na} \mathrm{NPO}_{4}$. Before part $\mathrm{B}$ of the cycle is performed this solution is removed and the cell is refilled with the same buffer now containing $2 \mathrm{mM}$ adenine. The $\mathrm{pH}$ is 7.5 throughout the cycle. The positive potential in part $\mathrm{B}$ of the cycle is lower than in the first part to limit the oxidation current. For the microcell $25 \mathrm{~mA} \mathrm{~cm}$ cm $^{-2}$ was shown to be a good value for the current density. We have noticed that exceeding this limit causes damage to the electrode surface resulting in low-intensity spectra with a high background. In figure 4 two SERS spectra of adenine made in the mini- and microcell are compared with a normal Raman spectrum of adenine. The SERS spectra are recorded with the potential of the silver electrode at $-0.6 \mathrm{~V}$ against SCE.

\section{Discussion}

Very good results were obtained with both cells. Comparison of our SERS spectra with a SERS spectrum of adenine previously reported in the literature (Ervin et al 1980) shows that we have gained a factor 10 in intensities. Using the in-plane ring breathing mode at $733 \mathrm{~cm}^{-1}$ we calculated an enhancement factor of $10^{6}$. The assumptions we made for this calculation were as follow: adenine lies flat on the surface covering $15 \times 10^{-2} \mathrm{~nm}^{2} /$ molecule and only the monolayer of material directly adsorbed to the surface contributes to the measured intensity. The last assumption is strictly incorrect as more than one layer may contribute to the measured Raman intensity. The calculated enhancement factor is therefore an upper limit.

We also obtained SERS spectra of guanine, cytosine and thymine having the same quality so SERS might be a sensitive technique for showing vibrational details of molecules adsorbed to a silver electrode.

The spectrum obtained with the microcell shows that using a microprobe arrangement very good SERS spectra can be obtained using low-intensity ( $1 \mathrm{~mW}$ ) laser light sources. We equipped the minicell with a stirring system. This was thought to be necessary to prevent polarisation effects during the anodisation cycle. However, using a gentle anodisation procedure we also obtained good results with the microcell which is not stirred. So a stirrer may not always be necessary.

\section{Acknowledgment}

This work was supported by the Netherlands Organisation for the Advancement of Pure Research (ZWO).

\section{References}

Chang R K and Furtak T E (ed.) 1982 Surface Enhanced

Raman Scattering (New York: Plenum)

Chen T T, Owen J F and Chang R K 1982 Surface enhanced

Raman scattering of water adsorbed on silver electrodes

Chem. Phys. Lett. 89 356-61

Ervin K M, Koglin E, Sequaris J M, Valenta P and

Nürnberg H W 1980 Surface enhanced Raman spectra of nucleic acid components adsorbed at a silver electrode J. Electroanal. Chem. 114 179-94

Buiteveld H, de Mul F F M, Greve J and Mud J 1982 Proc. 8th

Int. Conf. Raman Spectrosc. ed. J Lascombe and

P V Huong (Chichester: Wiley) pp 817-8 